\title{
DO BOLETIM INFORMATIVO ÀS REDES SOCIAIS: A EVOLUÇÃO NA COMUNICAÇÃO SBQ-ASSOCIADO
}

\author{
Rossimiriam Pereira de Freitas* \\ Departamento de Química, Universidade Federal de Minas Gerais, 31270-901 Belo Horizonte - MG, Brasil
}

Recebido em 10/04/2017; aceito em 10/05/2017

\begin{abstract}
FROM BOLETIM INFORMATIVO TO SOCIAL MEDIA: THE EVOLUTION IN SBQ-MEMBERS COMMUNICATION. Boletim Informativo of SBQ has evolved over the last 35 years to reach more than 9.000 people such as students, teachers, and researchers around the country. This paper discusses its importance as a communication channel and its challenges to approach the public nowadays throughout the social media.
\end{abstract}

Keywords: Boletim SBQ, communication channel, social media

\section{HISTÓRICO}

A história da criação e consolidação de uma das mais importantes sociedades científicas da América é relatada, de forma brilhantemente crítica, no excelente artigo publicado pelos Professores Etelvino Bechara e Hans Viertler há exatos vinte anos. ${ }^{1}$ A leitura do texto deveria ser obrigatória para todos aqueles que ingressam nos estudos superiores na área de Química, para compreensão do difícil passado dos seus predecessores, do relevante caminho percorrido até aqui e da importância do seu próprio papel para o futuro da área no país. Nos dias de hoje, é difícil para muitos de nós imaginarmos que, no ano da criação da Sociedade Brasileira de Química (SBQ) em seu formato atual, em 1977, "os químicos brasileiros, excetuando-se professores titulares e alguns outros mais titulados, simplesmente não se conheciam" e que "uma das tarefas dos diretores e conselheiros da SBQ nas primeiras reuniões anuais era a de apresentar os pesquisadores uns aos outros". ${ }^{1}$

De sua criação até o presente são quarenta anos de história da SBQ e, nesse caminho, muitas coisas mudaram. Entretanto, a necessidade de congregar os químicos e de mobilizá-los em prol de interesses comuns, como o fortalecimento da área no país, a geração e divulgação do conhecimento químico e a atuação política na universidade e na sociedade, sempre permeou todas as ações das diferentes gestões de Diretorias e Conselhos da Sociedade. E foi dentro desse contexto, de premência de mobilização, capilarização de informação, fortalecimento e motivação institucional que foi planejada a criação de um Boletim Informativo ao associado, ideia sempre presente na mente dos fundadores e que foi capitaneada por uma das mais combatentes figuras dos primeiros tempos da Sociedade, o Professor Eduardo Peixoto. E assim nasceu, em setembro/outubro de 1982, na presidência do Professor Fernando Galembeck, o primeiro Boletim Informativo da SBQ, ainda na era pré-informática (Figura 1). Sob a responsabilidade do então $1^{\circ}$ secretário Professor Marco-Aurélio De Paoli, contendo textos datilografados que eram levados à gráfica para impressão em frente e verso (reflexo da situação financeira da Sociedade na época), os boletins eram encaminhados para São Paulo onde a secretaria da SBQ se encarregava de enviá-los, pelo correios, aos associados da Sociedade. O trabalho envolvia também datilografar as quase mil etiquetas com os endereços dos destinatários, nos tempos que antecederam a era do computador.

Com uma frequência bimestral nas suas tiragens iniciais, o Boletim Informativo rapidamente tornou-se popular e funcional como

*e-mail: rossimiriam@qui.ufmg.br

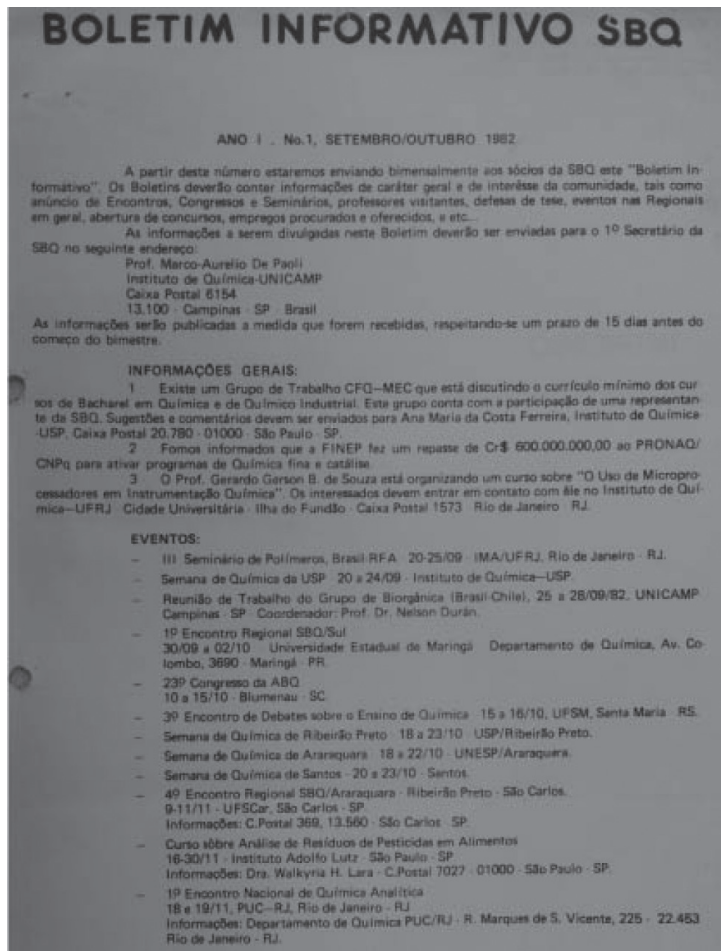

Figura 1. Primeiro Boletim informativo da SBQ (setembro/outubro1982)

meio de divulgação de notícias e eventos que ocorriam de norte a sul do país e também como canal de difusão de decisões tomadas pela Diretoria e Conselho da Sociedade em suas reuniões. Na sua versão impressa, cinco foram os editores que assumiram, durante 14 anos, a responsabilidade pela publicação do Boletim. Marco-Aurélio De Paoli, do IQ da UNICAMP, ficou responsável por toda a fase inicial da publicação, de 1982 até 1988, com um intervalo no ano de 1987, quando assumiu a editoria o Professor Oswaldo Luiz Alves, também do IQ da UNICAMP. Na sequência (1988-1989), e pela primeira vez, teve-se uma mulher como editora do Boletim, a Professora Helena Ferraz do IQ-USP, que havia sido tesoureira da SBQ na gestão anterior. Em seguida, sob a editoria do Professor Eduardo Peixoto (1990-1993), também do IQ-USP, a publicação passou a se chamar "Boletim da SBQ", mudando o seu formato gráfico e conteúdo, que passou a trazer em cada edição a história de um elemento químico. Na editoria seguinte, assumida pelo Professor Romeu Cardozo Rocha Filho da UFSCar, então Secretário Geral da SBQ, o Boletim chegou 
a oito páginas e publicava a cada trimestre uma edição especial com a agenda do período.

Algumas mudanças importantes ocorreram a partir de 1996, como consequência da informatização da Secretaria da SBQ iniciada pelo próprio Professor Romeu Cardoso Rocha Filho em 1992. Naquela época a internet já começara a revolucionar a vida das pessoas e foi por isso que, em 1996, o Boletim tornou-se eletrônico, recebendo o nome de "Boletim Eletrônico da SBQ". Editado pelo então Secretário Geral Luiz Carlos Gomide Freitas, da UFSCar, o Boletim Eletrônico (BE) passou a ser enviado aos associados na forma de e-mails. A inovação permitiu mais agilidade, aumento do espaço editorial sem aumento de custos e a divulgação de edições semanais, com conteúdo mais abrangente para toda a comunidade de leitores no país. Criado para ser o principal canal de comunicação entre a Diretoria da SBQ e os associados, a versão digital trouxe também um importante desafio do ponto de vista gráfico ficando, na editoria seguinte, sob a responsabilidade do Professor Paulo Cezar Vieira (1998-2000), da UFSCar, que trabalhou na forma, no conteúdo e aumentou a periodicidade e a tiragem da publicação, sendo então publicados 168 boletins em dois anos. Também foi em 1998 que o Boletim da SBQ ficou acessível a qualquer pessoa que se inscrevesse para recebê-lo, não necessariamente sendo associado SBQ. Um recenseamento eletrônico realizado na época mostrou que 1850 eram os assinantes que o recebiam via e-mail. No ano 2000, assumiu a editoria o então secretário geral Professor Luiz Carlos Dias, do IQ da UNICAMP, em uma atuação que seria a mais longeva de todo o percurso do Boletim (2000-2006). O Professor Luiz Carlos Dias, nos seus seis anos como editor, foi responsável pelo impressionante número de 514 edições e detém um recorde difícil de ser alcançado na história do Boletim. A partir de 2006, a edição do Boletim Eletrônico ficou definitivamente a cargo dos secretários gerais de cada gestão e, em janeiro de 2007, sob a direção do Professor Norberto Peporine Lopes da USP-RP, incorporou um novo projeto gráfico com o uso de fotos, cores e até animações, mas sendo exibido ainda em uma única página. O sucessor na editoria, secretário geral Professor Luis Catalani do IQ-USP passou a contar, pela primeira vez, com um assessor de imprensa, o jornalista Carlos Martins, que ocasionalmente ficava responsável por entrevistas e redação de matérias de interesse da Sociedade, incluindo textos específicos sobre as Reuniões Anuais. Além disso, o Boletim passou a ser editado na forma de News Letters, facilitando o manuseio digital pelos leitores. Entre os anos de 2009-2010, 149 boletins foram editados.

Acompanhando a rápida evolução da sociedade informatizada e das formas de comunicação, em dezembro de 2009 o Professor Luiz Catalani introduziu a SQB no Twitter, na primeira incursão da Sociedade nas redes sociais, cuja popularidade explodia no país. Em 2010, assumiu a editoria o secretário geral Professor Adriano D. Andricopulo, da UFSCar, e o veículo deixou de ser enviado apenas na forma de e-mail, passando a ter espaço próprio no endereço http:// boletim.sbq.org.br. A então formada comissão de informática da SBQ, constituída pelos professores Luiz Henrique Catalani, Luiz Carlos Dias, Norberto Peporine Lopes e Adriano D. Andricopulo deu ao Boletim um novo formato gráfico, mais moderno e flexível, criando seções para organização das informações. A nova proposta advinha do crescente número de notícias que chegavam semanalmente de todo o país para divulgação, incluindo oportunidades profissionais e eventos na área, informações estas que precisavam de nova sistematização, sendo o novo formato usado, com poucas modificações, até os dias atuais. A SBQ contava então com 8112 endereços de e-mails cadastrados como recebedores semanais do seu Boletim Eletrônico nas quintas-feiras. A periodicidade semanal foi instituída com a edição de 96 números a cada mandato. Informações urgentes sobre as Reuniões Anuais, notas de falecimento e datas especiais deram origem aos hoje chamados "boletins especiais". Também foi na gestão do secretário geral Professor Adriano Andricopulo que se iniciou a série de Boletins Eletrônicos no formato de "Revistas Eletrônicas", publicadas logo após as Reuniões Anuais da SBQ com os principais detalhes do evento.

A gestão seguinte (2012-2014), assumida pelo então secretário geral Professor Aldo José Gorgatti Zarbin da UFPR (primeiro editor fora do estado de São Paulo), marcou a entrada, em janeiro de 2013, da SBQ no Facebook, uma das mais famosas redes sociais de todos os tempos. A página oficial da Sociedade Brasileira de Química no Facebook passou então a reproduzir semanalmente, a partir do número 1060, as principais notícias do Boletim Eletrônico. A primeira notícia divulgada no Facebook, em 17 de janeiro de 2013, foi, coincidentemente, sobre a candidatura do Brasil para sediar o Congresso Mundial da IUPAC em 2017. Com pesado investimento em divulgação no Facebook na gestão 2014-2016, feito pelo então secretário geral Professor Luiz Fernando da Silva Junior do IQ-USP, a página da SBQ no Facebook começou a receber um maior número de visitas e "curtidas", principalmente de jovens estudantes e professores. Páginas também foram criadas para divulgar as Reuniões Anuais da SBQ. Em outubro de 2015, a SBQ entrou também no Instagram, a rede social de fotos para usuários de Android e Iphone, que permite a criação das famosas hashtags(\#). O canal da SBQ no youtube (SBQuímica), criado em janeiro de 2013, também passou a ser uma mídia usada para divulgação de vídeos de interesse da comunidade. Matérias produzidas por um novo assessor de imprensa, o jornalista Mario Henrique Viana, tornaram-se destaques em todas as edições semanais do Boletim e abordavam principalmente entrevistas com os grandes nomes presentes nas Reuniões Anuais.

Em 2016, assumiu novamente a editoria do Boletim uma mão feminina, agora pela primeira vez na versão eletrônica, atividade conduzida pela secretária geral Professora Rossimiriam Freitas, da UFMG-MG. Novo recenseamento, realizado em março de 2017, com eliminação de endereços de e-mails não ativos (um grande problema desde o ano de 1998), mostrou que 7564 pessoas recebiam efetivamente o Boletim Eletrônico da SBQ. A maior parte dos servidores, institucionais ou não, desenvolveram serviços de bloqueio automático de e-mails, o que gera uma necessidade constante de atualização de listas e endereços eletrônicos. Por outro lado, com 9.205 seguidores registrados e atualizações diárias, a página do Facebook da SBQ conhece um estrondoso sucesso de "curtidas" e "compartilhamentos", tendo uma taxa de resposta de $100 \%$ e um tempo de resposta de 30 minutos, tarefa executada diariamente pela Webmaster/SBQ e pela própria Secretária Geral. Já no Twitter, 2.326 era o número de seguidores da SBQ registrados, também em março de 2017. Em relação ao conteúdo editorial, as matérias de destaque no Boletim passaram a incluir também textos preparados sobre os todos os programas de pós-graduação em química do Brasil, o que gerou uma excelente resposta dos leitores de todos os cantos do país. Em 2017, ano de comemoração dos quarenta anos da SBQ, duas novas seções foram criadas como tentativa de mobilizar os associados com a data histórica, a "Causos SBQ", relatando fatos pitorescos que aconteceram nesses 40 anos de existência, e a seção "Documenta SBQ!", para registrar fatos históricos, documentos e fotos de época da Sociedade. Com a contribuição do Facebook, algumas matérias do Boletim passaram a ser visualizadas milhares de vezes, compartilhadas centenas de vezes e a interação com o associado químico ou simpatizante atingiu um novo grau de modernidade.

Até o momento, foram nove os editores responsáveis pelos 21 anos de vida eletrônica do Boletim, desde 1996 (Figura 2). O BE integra hoje uma das atividades editoriais da PubliSBQ (publicações SBQ), o órgão que se ocupa de todos os trabalhos de difusão científica e técnica da Sociedade e que tem plataforma única em http://publi. sbq.org.br/index.php. 

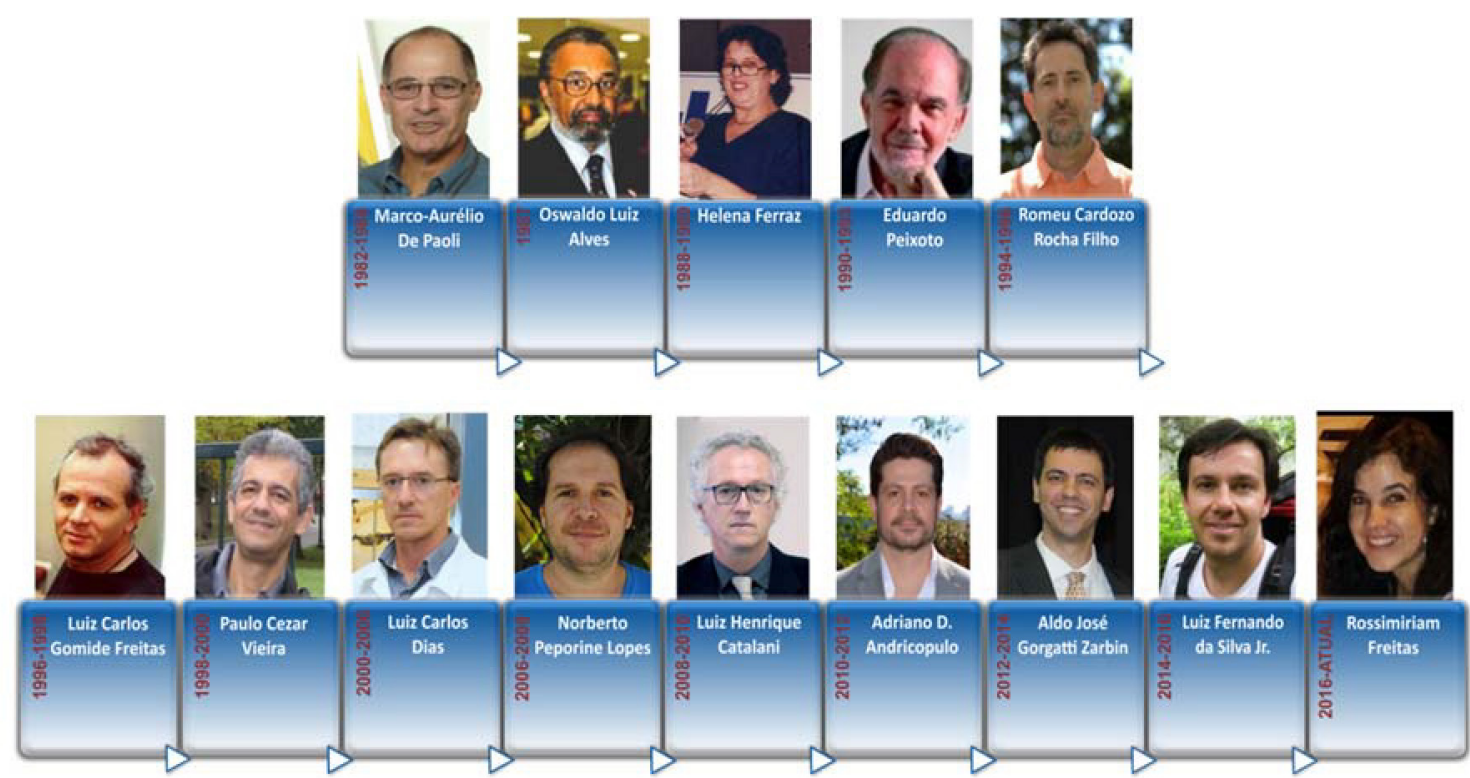

Figura 2. Linha do tempo: editores do Boletim da $S B Q$

\section{AVANÇOS E DESAFIOS}

Ao longo de toda a sua trajetória, o Boletim Eletrônico da SBQ tornou-se uma presença permanente e uma referência para os químicos do país, principalmente para aqueles ligados ao meio acadêmico, e também para estudantes de química e de ciências correlatas, estudantes do ensino médio, profissionais da área e pessoas com interesse geral por química e assuntos relacionados, sem necessariamente envolvimento profissional. O maior veículo de comunicação da SBQ passou por diversas transformações ao longo dos anos e, cada um dos seus editores enfrentou, à sua forma, o desafio de realizar um trabalho competente, sério e dedicado, à custa de muito esforço pessoal. Com alterações de forma, conteúdo e estilo, os nomes desses editores passaram a ser familiares aos leitores do Boletim, por integrarem o cotidiano das notícias da SBQ no decorrer dos últimos 35 anos.

$\mathrm{Na}$ sua origem o Boletim teve um papel fundamental na integração nacional entre os químicos (que se distribuíam rapidamente por um número crescente de estados e municípios do país) e no fortalecimento das revistas científicas da Sociedade, que vieram a ter forte e fundamental importância na consolidação da pós-graduação e da ciência química no Brasil. Na época de sua criação, no biênio 83/84, eram 24 os cursos de pós-graduação em química no país, que formaram 599 mestres e 276 doutores, números que cresceriam substancialmente até atingir 61 programas em 2014, com a formação de 1064 mestres e 579 doutores. ${ }^{2}$ Na sua criação, o Boletim era a principal fonte de comunicação da Diretoria e Conselho da SBQ com o associado, em uma época em que endereços e-mails, websites, redes sociais e postagens digitais eram invenções extraordinárias demais para serem pressagiadas. Nas suas primeiras décadas de existência o Boletim, com a publicação de artigos de opinião e de análises reflexivas de associados SBQ, contribuiu também para a estruturação, amadurecimento e fortalecimento deste "ser coletivo"3 tão almejado pelos fundadores da Sociedade. Já com a ampliação do seu público alvo para não associados, a publicação assumiu também um papel mais geral de acompanhamento e divulgação dos fatos relevantes sobre todas as políticas de ciência, educação, tecnologia e inovação no país nas áreas de interesse da Sociedade. Além de permanecer alerta sobre todos esses tópicos, nos dias de hoje a publicação ainda preza por divulgar fielmente, assim como desde o seu início, todos os novos números das revistas da Sociedade, o Journal of the Brazilian Chemical Society, a Química Nova, a Química Nova na Escola e a
Revista Virtual de Química, e impulsionar a propagação dos trabalhos relatados nessas edições. O reconhecimento nacional e internacional da ciência desenvolvida pelos químicos do país, com destaque para seus associados, é frequentemente comemorado em suas edições, através da publicação de seus prêmios, cargos de destaque, títulos de relevância. O Boletim também sempre deu voz a manifestações, a cada vez que um fato grave veio atingir as políticas nacionais de educação, a ciência de forma geral, e a química em particular. E não há dúvida de que, em todos estes anos de existência da SBQ, estas áreas enfrentaram no Brasil situações que foram (e ainda são), ao mesmo tempo, grandes ataques e desafiadores incentivos de todas as naturezas. Assim como nos seus primórdios, o BE continua também a desempenhar também o papel básico de prestador de serviços, publicando semanalmente informes sobre os mais variados eventos da área no país, concursos e empregos, assim como oportunidades nacionais e internacionais para prêmios, dentre outras divulgações.

A instalação de um contador de visitas nas matérias do Boletim a partir do número 1132 (31 de julho de 2014), assim como o uso das ferramentas estatísticas do Facebook, permite atualmente ao editor avaliar as notícias que mais impactam o leitor e isso poderá talvez nortear, se necessário, possíveis modificações em sua linha editorial no futuro. As notícias sobre a divulgação dos números novos das revistas e obras publicadas pela Sociedade são muito compartilhadas pelos leitores e autores, ressaltando o grande impacto da PubliSBQ ${ }^{4}$ no fortalecimento da educação química e pós-graduação no país. A defesa da ciência através de manifestos e cartas publicados por membros de sua Diretoria e/ou Conselho continuam sendo muito bem recebidos, o que talvez traduza a vontade dos químicos de todas as gerações de que a SBQ continue a ser a voz firme e atuante que sempre defendeu interesses gerais e urgentes da comunidade. Intervenções de reconhecidos pesquisadores químicos na grande mídia, sobre assuntos polêmicos que atingem diretamente a população de forma geral, também têm grande impacto na sociedade e precisam ser urgentemente incentivadas pela SBQ. Algumas das notícias de maior impacto, publicadas a partir da instalação do contador de visitas em 2014 nas páginas do Boletim Eletrônico, bem como algumas das notícias mais compartilhadas no Facebook, dentro deste contexto, são apresentadas nas Tabelas 1 e 2, respectivamente.

A popularização da web, a multiplicação de blogs e portais sobre ciência no país e no mundo e o número quase infinito de possibilidades de informação disponíveis na rede trazem um grande desafio para o 
Tabela 1. Notícias mais visitadas no Boletim Eletrônico da SBQ após instalação do contador de visitas em julho de 2014

\begin{tabular}{|c|c|c|c|}
\hline Matéria & Número Boletim & Data & Visitas \\
\hline Manifestação da SBQ em resposta à coluna de Denise Fraga da Folha de São Paulo & 1135 & $14 / 08 / 2014$ & 21815 \\
\hline $\begin{array}{l}\text { Resumo do Relatório Técnico-Científico sobre os testes químicos realizados com as cápsulas da } \\
\text { "Pílula do Câncer" }\end{array}$ & 1217 & $20 / 04 / 2016$ & 6542 \\
\hline Novo corte de verbas deixa universidades federais alarmadas & 1233 & $18 / 08 / 2016$ & 2869 \\
\hline Liberação da 'Pílula do Câncer' expõe atropelo da ciência pela política & 1217 & $20 / 04 / 2016$ & 1864 \\
\hline SBQ volta de Coreia do Sul sob os holofotes da química mundial & 1184 & $20 / 08 / 2015$ & 1438 \\
\hline Manifesto da SBQ contra Projeto de Lei no. 4.486 de 2016 & 1238 & $22 / 09 / 2016$ & 1427 \\
\hline
\end{tabular}

Tabela 2. Posts mais compartilhados da página do Facebook da Sociedade Brasileira de Química

\begin{tabular}{|c|c|c|c|}
\hline Post & Compartilhamentos & Data & Pessoas alcançadas \\
\hline QNInt: o Portal da SBQ para Química do ensino médio à pós-graduação & 381 & $19 / 03 / 2015$ & 163.618 \\
\hline 18 de junho- Dia do Químico & 331 & $17 / 07 / 2016$ & 44.201 \\
\hline Origens da Química no Brasil revela os primórdios da ciência & 293 & $08 / 10 / 2015$ & 91.460 \\
\hline SBQ volta de Coreia do Sul sob os holofotes da química mundial & 257 & $20 / 08 / 2015$ & 146.142 \\
\hline Angelo da Cunha Pinto (1948-2015) & 234 & $07 / 10 / 2015$ & 37.528 \\
\hline SBQ se manifesta contra cortes de bolsas de Iniciação Científica & 162 & 08/08/2016 & 17.026 \\
\hline "Brasil é um paraíso para se trabalhar em produtos naturais" & 65 & $30 / 08 / 2016$ & 11.623 \\
\hline
\end{tabular}

Boletim nos próximos anos e uma reflexão se faz necessária sobre o seu papel na comunicação entre a SBQ e o público. As pessoas recebem hoje um grande número de e-mails, diariamente, e estão excessivamente expostas a notícias das mais variadas fontes, em poucos cliques. Atraí-las para a leitura de um Boletim semanal de notícias, veiculado as quintas-feiras, é um desafio. A velocidade com que a informação é propagada nos dias atuais é muito maior que há dez, vinte anos e o contato semanal com o sócio, em algumas situações, já será defasado. Assim, o papel das redes sociais na comunicação da SBQ com o público tem ficado bastante claro para os recentes editores do Boletim, que têm se empenhado em dividir a tarefa de edição do Boletim com a frequência diária às redes. Isso é um caminho sem volta. Já a edição do Boletim Eletrônico demanda atualmente um alto investimento da SBQ em conteúdo jornalístico original, em uma árdua seleção de principais notícias semanais em um universo de informações profícuas, além de uma velocidade rápida de reação em relação aos acontecimentos recentes.

Apesar de ter se consolidado como a publicação que acompanhou de perto as angústias e sucessos dos químicos acadêmicos brasileiros nas últimas quatro décadas, é provável que o Boletim Eletrônico não tenha ainda completamente explorado o seu potencial de promoção da química para a Sociedade Brasileira visto que, dentre todas as publicações da SBQ, ele representa um dos mais populares canais de comunicação. A rápida evolução nos meios de comunicação mostra que o desafio de tornar o Boletim uma publicação atraente e forte é constante. Os últimos dados sobre conteúdo editorial indicam que a participação de reconhecidos químicos brasileiros na análise de assuntos polêmicos de interesse nacional é importante para a criação de um elo seguro de identificação institucional. Essas intervenções diretas de associados podem mostrar, para o público em geral, a real contribuição da Química para a sociedade e dar a esta ciência o reconhecimento nacional de que, sem Química, não há desenvolvimento, não há melhoria nas condições de vida de um povo, de um país ou de um planeta.

\section{AGRADECIMENTOS}

A autora agradece a Sra. Dirce Campos, secretária executiva da SBQ, e o Professor Etelvino Bechara, ex-presidente da SBQ e atual Conselheiro, pela leitura da parte histórica deste texto, e a Webmaster da SBQ, Srta. Rosangela Fernandes, pelo levantamento de dados que compõem o manuscrito.

\section{REFERÊNCIAS:}

1. Bechara, E.J. H.; Viertler, H.; Quim. Nova 1997, 20,63.

2. https://www.cgee.org.br/documents/10182/734063/Mestres_ Doutores_2015_Vs3.pdf

3. Peixoto, E. M. A.; Quim. Nova 2004, 1, 26.

4. Conselho de Editores; Quim. Nova 2014, 37, 583. 